\title{
EVALUASI PENERAPAN GOOD CORPORATE GOVERNANCE PADA PT BUMN ABC, INDONESIA
}

\author{
Johny Sudharmono ${ }^{1}$, Hetty Karunia Tunjungsari ${ }^{2 *}$ \\ ${ }^{1}$ Jurusan Magister Akuntansi, Fakultas Ekonomi dan Bisnis, Universitas Tarumanagara Jakarta \\ Email: johnys@fe.untar.ac.id \\ ${ }^{2}$ Jurusan Magister Manajemen, Universitas Tarumanagara Jakarta \\ Email: hetty@fe.untar.ac.id \\ *penulis korespondensi
}

Masuk : 17-04-2020, revisi: 30-04-2021, diterima untuk diterbitkan : 30-04-2021

\begin{abstract}
ABSTRAK
Penelitian ini bertujuan untuk melakukan evaluasi atas "Penerapan Tata Kelola Perusahaan yang Baik (Good Corporate Governance/GCG)" pada PT ABC periode tahun 2020. Penelitian ini menggunakan desain studi kasus dengan metode asesmen yang mengacu pada sistem penilaian yang ditetapkan dalam "Keputusan Sekretaris Kementerian BUMN Nomor : SK16/S.MBU/2012, tanggal 06 Juni 2012 tentang Indikator/Parameter Penilaian dan Evaluasi atas Penerapan Tata Kelola Perusahaan Yang Baik (Good Corporate Governance) pada BUMN di Indonesia." Data yang digunakan dalam kajian ini adalah data yang dikumpulkan dari berbagai sumber (the triangulation of data sources), yaitu: dokumen hasil Asesmen Penerapan GCG Tahun 2020 pada PT ABC, kuesioner, wawancara, dan arsip perusahaan. Hasil kajian menunjukkan bahwa secara menyeluruh hasil asesmen penerapan GCG tahun 2020 pada PT ABC sudah berjalan sangat baik. Namun demikian, dalam rangka penerapan GCG secara konsisten dan berkelanjutan masih terdapat beberapa area yang masih memerlukan perbaikan (area for improvement), Hasil kajian ini adalah dapat disusunnya suatu rekomendasi strategik dalam rangka meningkatkan efektivitas penerapan GCG dalam suatu model yang terintegrasi dengan strategi korporasi yang bermanfaat bagi perkembangan keilmuan dalam bidang Strategic Management, dan Governance, Risk, and Compliance (GRC) dan bagi penelitian selanjutnya.
\end{abstract}

Kata Kunci: GCG, asesmen, strategi korporasi, GRC-Strategy

\begin{abstract}
This study discusses the Implementation of Good Corporate Governance (GCG) at PT ABC for the period of 2020. This research uses a case study design with an assessment method that refers to the assessment system stipulated in the Decree of the Secretary of the Ministry of SOEs Number: SK-16 / S.MBU / 2012, dated June $6^{\text {th }} 2012$, concerning Indicators/Parameters for Assessment and Evaluation of the Implementation of Good Corporate Governance in State owned Enterprise in Indonesia. The data used in this study is collected from various sources (the triangulation of data sources), namely: documents of the 2020 GCG Implementation Assessment at PT ABC, questionnaires, interviews, and company archives. The results of the study show that overall assessment results of the implementation of GCG in 2020 at PT ABC have been going very well. However, in the context of implementing GCG consistently and sustainably, there are several areas that still need improvement (areas for improvement). The results of this study show that a strategic recommendation can be drawn up in order to improve the effectiveness of GCG implementation in an integrated model with a useful corporate strategy for scientific developments in the fields of Strategic Management, and Governance, Risk, and Compliance (GRC) and for further research.
\end{abstract}

Keywords: GCG, assessment, corporate strategy, GRC-Strategy

\section{PENDAHULUAN Latar Belakang}


Kerangka kerja tata kelola perusahaan (corporate governance) yang efektif perlu didukung oleh cara-cara yang efektif untuk memastikan integritas mereka seperti meliputi analisis keuangan, pialang, dan lembaga pemeringkatan yang efektif. Di Indonesia, Badan Usaha Milik Negara (BUMN) penerapan Tata Kelola Perusahaan yang Baik atau dikenal sebagai Good Corporate Governance merupakan bagian dari program transformasi yang digulirkan Kementerian BUMN sejak Oktober tahun 2019. Meskipun demikian, penerapan GCG di Indonesia masih menduduki peringkat di bawah Singapura, Malaysia dan Thailand (https://investor.id/editorial/gcg-di-bumn).

Dalam Peraturan Menteri Negara BUMN Nomor: PER-01/MBU/2011 tanggal 01 Agustus 2011 tentang Penerapan Tata Kelola Perusahaan Yang Baik (Good Corporate Governance) pada BUMN disebutkan bahwa: "(1) BUMN wajib menerapkan GCG secara konsisten dan berkelanjutan dengan berpedoman pada Peraturan Menteri ini dengan tetap memperhatikan ketentuan, dan norma yang berlaku serta Anggaran Dasar BUMN. (2). Dalam rangka penerapan GCG, Direksi menyusun GCG Manual yang diantaranya dapat memuat Board Manual, Risk Management Manual, Sistem Pengendalian Intern (Internal Control System), Sistem Pengawasan Intern, Sistem Pelaporan Pelanggaran (Whistleblowing System), Tata Kelola Teknologi Informasi, dan Pedoman Perilaku Etika (Code of Conduct) atau biasa disebut Kode Etik Perusahaan.”

Penerapan GCG memegang peran strategis baik bagi Kementerian BUMN maupun bagi BUMN itu sendiri beserta anak perusahaannya. Oleh sebab itu, Kementerian BUMN melalui Sekretaris Kementerian BUMN mengeluarkan Surat Keputusan nomor : SK-16/ S. MBU/ 2012 tanggal 06 Juni 2012 yang berisikan tentang "Indikator/ Parameter Penilaian dan Evaluasi atas Penerapan Tata Kelola Perusahaan Yang Baik(Good Corporate Governance) Pada BUMN". Dalam Surat Keputusan tersebut disebutkan bahwa "dalam upaya perbaikan dan peningkatan kualitas penerapan GCG, BUMN wajib melakukan pengukuran terhadap penerapan GCG, sehingga apabila masih terdapat kekurangan dalam pengimplementasiannya, BUMN dapat segera menetapkan rencana tindak lanjut (action plan) yang diperlukan." Lebih lanjut, sesuai Surat Keputusan Kementerian BUMN nomor: SK-16/ S. MBU/ 2012 tanggal 06 Juni 2012, "Pengukuran terhadap penerapan GCG dilakukan dalam bentuk:

1. Penilaian (Assessment), yaitu program untuk mengidentifikasi pelaksanaan GCG di Perusahaan, melalui pengukuran yang dilaksanakan secara berkala setiap 2 (dua) tahun;

2. Evaluasi (Review), yaitu program untuk mendeskripsikan tindak lanjut penerapan GCG di Perusahaan, melalui pengukuran yang dilaksanakan pada tahun berikutnya setelah penilaian sebagaimana dimaksud pada butir 1, yang meliputi evaluasi terhadap hasil penilaian dan tindak lanjut atas rekomendasi perbaikan."

Adapun tujuan dilakukannya Asesmen Penerapan GCG sebagaimana dijelaskan dalam "Surat Keputusan tersebut adalah sebagai berikut:

1. Mengukur kualitas penerapan GCG di Perusahaan melalui penilaian tingkat pemenuhan kriteria dengan kondisi nyata yang diterapkan dengan pemberian skor dan kategori kualitas penerapannya,

2. Mengidentifikasi kekuatan dan kelemahan penerapan GCG di Perusahaan, serta mengusulkan rekomendasi perbaikan untuk mengurangi celah (gap) antara kriteria dengan kondisi nyata penerapannya,

3. Memonitor konsistensi penerapan GCG di Perusahaan dan memperoleh masukan untuk penyempurnaan dan pengembangan Kebijakan GCG di lingkungan Perusahaan.” 
Penelitian ini dilakukan dengan tujuan untuk mendapatkan hasil Asemen Penerapan GCG pada PT ABC, memahami bagaimana hasil penerapan GCG tahun 2020 pada PT ABC, area mana yang perlu dilakukan perbaikan (area for improvement), dan merekomendasikan strategi yang tepat untuk meningkatkan efektivitas penerapannya.

\section{Tujuan Penelitian}

Penerapan Tata Kelola Perusahaan yang Baik (GCG) merupakan syarat mutlak yang harus diimplementasikan oleh setiap unsur Badan Usaha Milik Negara di Indonesia. Setiap tahunnya, penerapan GCG akan dievaluasi untuk mengukur kualitas penerapannya dan kemudian dinilai konsistensi penerapannya. Di tahun 2020, situasi pandemi COVID-19 memunculkan dampak yang luas bagi perusahaan di berbagai skala dan bentuk kepemilikan, tak terkecuali di PT ABC. Dampak tersebut dikhawatirkan dapat mempengaruhi kualitas penerapan GCG di PT ABC di tahun 2020.

Merujuk pada permasalahan di atas, tujuan penelitian ini sebagai berikut:

1. Untuk mengukur kualitas penerapan GCG di PT ABC pada tahun 2020.

2. Untuk mengetahui faktor-faktor yang merupakan kekuatan dan kelemahan penerapan GCG di PT ABC pada tahun 2020.

3. Mengetahui konsistensi penerapan GCG di PT ABC di tahun 2020.

\section{Telaah Kepustakaan}

Tata Kelola Perusahaan yang Baik dikenal juga sebagai Good Corporate Governance atau lebih populer juga dengan istilah GCG telah banyak dipraktikkan oleh perusahaan-perusahaan di seluruh dunia. Sarah (2017) mengemukakan bahwa perusahaan yang menerapkan GCG akan mendapatkan sejumlah manfaat sebagai berikut: (1) pengelolaan yang unggul/berkualitas, (2) tingkat transparansi manajemen yang tinggi, (3) Pemengang Saham mendapatkan manfaat atas kinerja terbaik dari Perusahaan, (4) reputasi dan pengakuan yang luas dari berbagai pihak, (5) mengurangi pemborosan sumber daya Perusahaan (6) mengurangi risiko, mismanajemen dan korupsi, (7) keberhasilan ekonomi dalam jangka panjang.

"GCG adalah prinsip-prinsip yang mendasari suatu proses dan mekanisme pengelolaan Perusahaan berlandaskan peraturan Perundang-undangan dan etika berusaha (Peraturan Menteri Negara BUMN Nomor 01 Tahun 2011)". The National Association of Corporate Directors, mendefinisikan Governance sebagai "karakteristik yang memastikan bahwa sasaran dan rencana strategik jangka panjang yang telah ditetapkan dan struktur manajemen telah tepat untuk mencapai sasaran tersebut, pada saat bersamaan memastikan bahwa struktur berfungsi untuk mengelola integritas, reputasi, dan tanggung jawab Perusahaan terhadap berbagai pihak yang berkepentingan”. (David \& David, 2017).

Survei dari McKinsey menyatakan bahwa investor bersedia untuk membayar lebih dari $16 \%$ terhadap saham Perusahaan jika diketahui memiliki Good Corporate Governance. Investor menjelaskan bahwa mereka mau membayar lebih karena berpendapat "(1) good governance mengarah kepada kinerja lebih baik dari waktu kewaktu, (2) good governance menurunkan risiko Perusahaan, dan (3) governance merupakan isu strategik utama." (Wheelen et al., 2018).

Di Indonesia, penerapan GCG dapat ditemukan baik di perusahaan swasta maupun perusahaan BUMN. Dalam Peraturan Menteri Negara BUMN Nomor 01Tahun 2011 dinyatakan bahwa "BUMN wajib melakukan Pengukuran terhadap penerapan GCG dalam bentuk penilaian (assessment) dan evaluasi (review). Pelaksanaan penilaian dan evaluasi dilakukan dengan 
menggunakan Indikator/Parameter yang ditetapkan oleh Sekretaris Kementerian BUMN. Hasil pelaksanaan penilaian dan evaluasi dilaporkan kepada RUPS/Menteri bersamaan dengan penyampaian Laporan Tahunan.”

Lebih lanjut, dalam Keputusan Sekretaris Kementerian BUMN Nomor 16 Tahun 2012 dinyatakan bahwa "Indikator/Parameter Penilaian dan Evaluasi atas Tata Kelola Perusahaan yang Baik (Good Corporate Governance) pada BUMN, selanjutnya disebut Indikator/Parameter GCG, ditetapkan sebagaimana tercantum dalam Lampiran yang tidak terpisahkan dari Keputusan ini. Indikator/Parameter GCG dimaksud digunakan sebagai pedoman dalam melaksanakan Penilaian dan Evaluasi atas penerapan tata Kelola Perusahaan yang Baik pada BUMN.”

Terkait dengan Rapat Umum Pemegang Saham, dalam Peraturan Menteri Negara BUMN Nomor 12 Tahun 2012 disebutkan bahwa: "Rapat Umum Pemegang Saham yang selanjutnya disebut RUPS adalah Organ Persero yang mempunyai wewenang yang tidak diberikan kepada Direksi atau Dewan Komisaris dalam batas yang ditentukan dalam Undang-undang Nomor 40 Tahun 2007 dan/atau Anggaran Dasar Perseroan. Dewan Komisaris adalah Organ Perusahaan Perseroan (Persero) yang bertugas melakukan Pengawasan dan memberikan Nasihat kepada Direksi dalam menjalankan kegiatan pengurusan Persero). Dewan Pengawas adalah Organ Perusahaan Umum (Perum) yang bertugas melakukan Pengawasan dan memberikan Nasihat kepada Direksi dalam menjalankan kegiatan pengurusan Perum. Direksi adalah Organ Persero atau Organ Perum yang berwenang dan bertanggung jawab penuh atas pengurusan Persero atau Perum, sesuai dengan maksud dan tujuan Persero atau Perum serta mewakili Persero atau Perum baik di dalam maupun di luar pengadilan sesuai dengan ketentuan Anggaran Dasar. Organ Pendukung Dewan Komisaris/Dewan Pengawas adalah Perangkat Dewan Komisaris/Dewan Pengawas yang berfungsi membantu Dewan Komisaris/Dewan Pengawas dalam melaksanakan tugasnya."

Keberhasilan penerapan GCG di perusahaan dijelaskan oleh Sudharmono (2014) yang mengutip sambutan Sekretaris Kementerian BUMN- Imam Apriyanto Putro bahwa "Disamping perangkat kesisteman tersebut, saya sependapat dengan ide penulis bahwa keberhasilan penerapan GCG di Peruahaan terletak pada factor manuasianya atau pelakunya, yaitu peran aktif dari tujuh aktor kunci, yaitu: (1) Pemegang Saham, (2) Direksi, (3) Dewan Komisaris/Dewan Pengawas, (4) Sekretaris Perusahaan, (5) Satuan Pengawasan Intern, (6) Manager, dan (7) Karyawan”. Untuk mengefektifkan penerapan GCG di lingkungan perusahaan, diperlukan sinergi yang didukung oleh strategi, struktur, nilai, kapabilitas dan mekanisme. Kolaborasi membutuhkan integrasi atau koordinasi antara berbagai fungsi dan bisnis dari portofolio investasi perusahaan, oleh karena itu, strategi, struktur organisasi, nilai, kapabilitas dan mekanisme yang digunakan oleh anggota organisasi merupakan alat penting untuk mencapai penciptaan kolaboratif (Sudharmono, 2016).

Menurut Wheelen et al. (2018), Corporate Strategy menggambarkan arah Perusahaan menyeluruh dalam hal pengembangan dan pengelolaan berbagai bisnis, yang secara umum terdiri dari tiga kategori utama: stability, growth, dan retrenchment. Adapun Thompson et al. (2018) menyatakan bahwa strategi perusahaan adalah serangkaian tindakan para Manajer untuk membuat lebih unggul dibandingkan dengan kompetitornya dan mencapai profitabilitas yang lebih super. Sasaran memformulasikan strategi yang baik adalah tidak hanya keberhasilan persaingan dan profit sementara dalam jangka pendek, namun lebih dari itu adalah keberhasilan yang dapat mendukung pertumbuhan dan kepastian Perusahaan di masa depan dalam jangka panjang. 
Moeller (2011) menyatakan bahwa Corporate/Enrerprise Governance, adalah suatu istilah yang mengacu secara luas pada peraturan, proses atau hukum dimana bisnis dioperasikan, diatur dan dikendalikan. Istilah ini dapat mengacu pada faktor- faktor internal yang ditetapkan oleh pegawai, pemegang saham, atau anggaran dasar dan tujuan Perusahaan, dan juga kekuatan dari eksternal seperti, konsumen, klien dan peraturan pemerintah. Risk management harus menciptakan nilai dan menjadi bagian integral dari proses-proses organisasi. Risk management menjadi bagian dari proses-proses pengambilan keputusan dan disesuaikan dengan cara yang sistematik dan terstruktur untuk menyelesaikan ketidakpastian yang dihadapi Perusahaan berdasarkan ketersediaan informasi terbaik. Compliance adalah kesesuaian atau kepatuhan terhadap external regulation. Agar penerapan Tata Kelola, Risiko, dan Kepatuhan dapat berjalan secara efektif dan selaras dengan Strategi Korporasi, maka diperlukan suatu sistem yang terintegrasi. JSM Management Consultant (2019) telah menawarkan suatu konsep yang disebut: "GRC-Strategy". GRC-Strategy merupakan suatu model kerangka kerja terintegrasi (Integrated Model Framework) yang mengintegrasikan "Tata Kelola (Governance), Risiko (Risk), dan Kepatuhan (Compliance)” ke dalam Strategi Korporasi (Corporate Stratgey).

\section{METODE PENELITIAN}

Metodologi yang digunakan sebagai acuan dalam melaksanakan kajian atas Penerapan GCG Tahun 2020 pada PT ABC berbasis pada sistem penilaian sesuai dengan "Keputusan Sekretaris Kementerian BUMN Nomor: SK-16/S.MBU/2012, tanggal 06 Juni 2012 tentang Indikator/Parameter Penilaian dan Evaluasi atas Penerapan Tata Kelola Perusahaan Yang Baik (Good Corporate Governance) pada BUMN, yang mencakup:

1. Tujuan. Tujuan dilakukannya Asesmen Penerapan GCG 2020 pada PT ABC, adalah sebagai berikut:

a. Mengukur kualitas penerapan GCG di Perusahaan melalui penilaian tingkat pemenuhan kriteria dengan kondisi nyata yang diterapkan dengan pemberian skor dan kategori kualitas penerapannya;

b. Mengidentifikasi kekuatan dan kelemahan penerapan GCG di Perusahaan, serta mengusulkan rekomendasi perbaikan untuk mengurangi celah (gap) antara kriteria dengan kondisi nyata penerapannya;

c. Memonitor konsistensi penerapan GCG di Perusahaan dan memperoleh masukan untuk penyempurnaan dan pengembangan Kebijakan GCG di lingkungan Perusahaan.

2. Periode. Pelaksanaan Asemen Penerapan GCG pada PT ABC ini adalah periode kegiatan tahun 2020.

3. Struktur. Struktur Asemen atas penerapan GCG pada dasarnya terdiri dari 5 (lima) elemen, yaitu :

a. 6 (Enam) Aspek penerapan GCG;

b. 43 (Empat puluh tiga) Indikator;

c. 153 (Seratus lima puluh tiga) Parameter;

d. 100 (seratus) total Bobot;

e. 568 Faktor Uji Kesesuaian (FUK).

Indikator/parameter Asesmen atas penerapan GCG adalah alat ukur untuk menilai kualitas inisiatif Perusahaan dalam menerapkan prinsip-prinsip GCG pada Perusahaan yang bersangkutan. Indikator/parameter tersebut dikelompokkan dalam 6 (enam) Aspek penerapan GCG yang terdiri dari :

a. Komitmen Terhadap Penerapan Tata Kelola Perusahaan yang Baik Secara Berkelanjutan;

b. Pemegang Saham dan RUPS/Pemilik Modal;

c. Dewan Komisaris/Dewan Pengawas; 

d. Direksi;
e. Pengungkapan Informasi dan Transparansi;
f. Aspek Lainnya."

Secara rinci setiap Aspek penerapan GCG tersebut terdiri dari beberapa parameter yang memilki bobot untuk penilaian masing-masing sebagaimana dapat dilihat pada tabel 1 di bawah ini:

Tabel 1. Struktur Penilaian Penerapan GCG

\begin{tabular}{cccccc}
\hline No. & Aspek & Indikator & Parameter & Bobot & $\begin{array}{c}\text { Faktor Uji } \\
\text { Kesesuaian } \\
\text { (FUK) }\end{array}$ \\
\hline I & Komitmen & 6 & 15 & 7 & 47 \\
II & Pemegang Saham & 6 & 25 & 9 & 68 \\
III & Dewan Komisaris & 12 & 43 & 35 & 167 \\
IV & Direksi & 13 & 52 & 35 & 201 \\
& Pengungkapan & & & & \\
V & Informasi \& & 4 & 16 & 9 & 78 \\
& Transparansi & & & & 7 \\
VI & Aspek Lainnya & 2 & 2 & 5 & $\mathbf{5 6 8}$
\end{tabular}

Tingkat pemenuhan faktor uji kesesuain (FUK), dikategorikan dalam 5 (lima) tingkatan, yaitu :

0 : Tidak ada;

0,25 : Memenuhi sebagian kecil persyaratan/kriteria;

0,50 : Memenuhi sebagian persyaratan/kriteria;

0,75 : Memenuhi sebagaian besar persyaratan/kriteria;

$1 \quad$ : Memenuhi seluruh persyaratan/kriteria.

Hasil Asesmen dimasukkan dalam klasifikasi kualitas penerapan GCG, sebagaimana tabel di bawah ini.

Tabel 2. Klasifikasi Kualitas Penerapan GCG

\begin{tabular}{clc}
\hline NO & NILAI/SKOR & $\begin{array}{c}\text { KLASIFIKASI KUALITAS } \\
\text { PENERAPAN }\end{array}$ \\
\hline 1 & Di atas 85 & Sangat Baik \\
2 & $75<$ Nilai/Skor $=85$ & Baik \\
3 & $60<$ Nilai/Skor $=75$ & Cukup Baik \\
4 & $50<$ Nilai/Skor $=60$ & Kurang Baik \\
5 & Nilai/Skor $=50$ & Tidak Baik \\
\hline
\end{tabular}

Pengumpulan data dilakukan melalui beberapa cara meliputi :

- Review Dokumen. Dokumen-dokumen untuk keperluan penilaian penerapan GCG disiapkan oleh PT ABC untuk periode tahun 2020.

- Kuesioner. Kuesioner digunakan untuk mengetahui tingkat pemahaman GCG atas setiap kelompok yang dinilai. 
- Wawancara. Wawancara terstruktur dilakukan untuk mendapatkan verifikasi atas dokumen-dokumen yang disiapkan oleh perusahaan. Selain itu, wawancara juga dilakukan untuk mengkonfirmasi hasil skor penilaian atas klasifikasi kualitas penerapan GCG yang diperoleh.

- Observasi. Peneliti melakukan observasi dalam kurun waktu 2 bulan untuk mendapatkan gambaran implementasi GCG di perusahaan.

Analisis data yang telah terkumpul dilakukan dengan cara melakukan pengujian kesesuaian penerapan dalam setiap parameter dan faktor uji kesesuaian (FUK) berdasarkan "klasifikasi sebagai berikut:

a. Keberadaan SOP/kebijakan/aturan main yang melandasi proses yang dilaksanakan oleh organ BUMN (Pemegang Saham/RUPS, Dewan Komisaris/Dewan Pengawas dan Direksi), termasuk kelengkapan muatan SOP/kebijakan/aturan main.

b. Diseminasi/sosialisasi SOP/kebijakan/aturan main.

c. Pemahaman para partisipan yang melaksanakan proses.

d. Rencana pelaksanaan atas proses sesuai SOP/kebijakan/aturan main.

e. Pelaksanaan proses di organ BUMN sesuai SOP/kebijakan/aturan main.

f. Keluaran/output atas proses yang dilaksanakan oleh organ BUMN.

g. Kualitas keluaran/output yang dihasilkan."

\section{HASIL DAN PEMBAHASAN}

Asesmen terhadap Penerapan GCG untuk Tahun 2020 pada PT ABC diperoleh hasil Asesmen Penerapan GCG pada PT ABC tahun 2020 mencapai total skor sebesar 89.67 dengan klasifikasi kualitas penerapan: "SANGAT BAIK". Ringkasan Hasil Asesmen ditampilkan pada tabel berikut:

Tabel 3. Ringkasan Hasil Asesmen Penerapan GCG Tahun 2020 PT ABC

\begin{tabular}{|c|c|c|c|c|c|}
\hline & & & & PAIAN & \\
\hline & ASPEK PENGUJIAN / & Вовот & TAH & UN 2020 & PENJELASAN* \\
\hline & INDIKATOR/PARAMETER & & & $\%$ & \\
\hline & & & SKOR & CAPAIAN & \\
\hline I & KOMITMEN $\quad$ TERHADAP & & & & \\
\hline & TATA KELOLA & & & & \\
\hline & PERUSAHAAN YANG BAIK & 7.00 & 6.45 & 92.12 & Sangat Baik \\
\hline & SECARA BERKELANJUTAN & & & & \\
\hline II & $\begin{array}{l}\text { PEMEGANG SAHAM DAN RUPS/ } \\
\text { PEMILIK MODAL }\end{array}$ & 9.00 & 8.48 & 94.22 & Sangat Baik \\
\hline III & $\begin{array}{l}\text { DEWAN KOMISARIS/ DEWAN } \\
\text { PENGAWAS }\end{array}$ & 35.00 & 31.67 & 90.49 & Sangat Baik \\
\hline IV & DIREKSI & 35.00 & 33.91 & 96.90 & Sangat Baik \\
\hline $\mathrm{V}$ & $\begin{array}{l}\text { PENGUNGKAPAN INFORMASI } \\
\text { DAN TRANSPARANSI }\end{array}$ & 9.00 & 8.27 & 91.93 & Baik \\
\hline VI & ASPEK LAINNYA & 5.00 & 1.25 & 25.00 & \\
\hline & TOTAL & 100.00 & 90.04 & 90.04 & \\
\hline & ASIFIKASI KUALITAS PENERAP & N GCG & & & Sangat Baik \\
\hline
\end{tabular}


Berdasarkan hasil Asesmen seperti yang tergambarkan pada tabel 3 di atas, secara umum dapat disimpulkan bahwa PT ABC telah memiliki fundamental sistem dan infrastruktur yang memadai. Namun demikian, hasil tersebut menunjukkan bahwa masih diperlukan sejumlah langkah-langkah perbaikan di beberapa area tertentu (Area for Improvement- AFI). Beberapa indikator yang pemenuhannya masih perlu dilakukan perbaikan (Area for Improvement AFI), adalah sebagai berikut:

\section{1) ASPEK KOMITMEN}

a) "Pedoman Tata Kelola Perusahaan Yang Baik (GCG Code) dan Pedoman Perilaku (Code of Conduct)" belum dimutakhirkan, mengingat Pedoman tersebut sudah lebih dari tiga (3) tahun;

b) Tingkat pemahaman karyawan di jajaran Perusahaan terhadap "Pedoman Tata Kelola Perusahaan yang Baik, Pedoman Perilaku, dan Kebijakan Pengendalian Gratifikasi" masih perlu ditingkatkan;

c) Kegiatan Sosialisasi "Pengendalian Grafitikasi" belum dilakukan kepada stakeholders eksternal.

\section{2) ASPEK PEMEGANG SAHAM DAN RUPS/PEMILIK MODAL}

a) Posisi Direktur Utama secara definitip masih belum ditetapkan oleh Pemegang Saham/RUPS;

b) Posisi Komisaris Utama secara definitip masih belum ditetapkan oleh Pemegang Saham/ RUPS;

c) Belum ada Pengesahan/ Persetujuan Rancangan RJPP Tahun 2018-2020;

d) Pengesahan RKAP belum dilaksanakan secara tepat waktu.

\section{3) ASPEK DEWAN KOMISARIS}

a) Belum ada telaah secara tertulis terhadap rancangan RJPP tahun 2018-2020 yang disampaikan oleh Direksi;

b) Belum ada pendapat dan saran secara tertulis terhadap rancangan RJPP tahun 2018-2020 untuk disampaikan kepada RUPS, untuk bahan pertimbangan keputusan RUPS;

c) Belum ada Pendapat dan saran secara tertulis terhadap Rancangan RKAP 2020 dan disampaikan pada RUPS untuk bahan pertimbangan keputusan RUPS;

d) Belum ada Pengawasan dan memberikan nasehat secara tertulis atas kebijakan beserta pelaksanaan kebijakan Direksi terhadap:

-Sistem Pengendalian Internal;

-Manajemen Risiko;

-Pengembangan Karir;

-Akuntansi dan Penyusunan laporan Keuangan;

-Pengadaan;

-Mutu \& Pelayanan.

e) Belum dilakukan Penilaian kinerja Direksi secara individu;

f) Masih terdapat area of improvement Hasil Asesmen GCG tahu 2019 yang belum ditindaklanjuti;

g) Piagam Komite Audit Tahun 2016, belum dimutakhirkan. 


\section{4) ASPEK DIREKSI}

a) Waktu penyampaian RKAP kepada RUPS belum tepat waktu;

b) Penempatan karyawan pada setiap level organisasi, masih ada jabatan yang lowong;

c) Pencapaian target Kinerja Direksi secara Individu, belum dibuat;

d) Kinerja Perusahaan masih perlu ditingkatkan agar dapat lebih baik dari tahun-tahun sebelumnya;

e) Piagam Internal Audit Tahun 2016, belum dimutakhirkan;

f) Pelaksanaan RUPS (RJPP 2018-2022 dan RKAP 2020), belum tepat waktu.

\section{5) ASPEK PENGUNGKAPAN INFORMASI DAN TRANSPARANSI}

a) Perusahaan belum berpartisipasi dan memperoleh penghargaan dalam bidang CSR, yaitu Sustainability Reporting Rating atau sejenisnya.

\section{6) ASPEK LAINNYA}

a) Perusahaan belum menjadi benchmark dan belum memiliki kinerja terbaik di sektor usaha BUMN atau di industrinya.

Agar Tata Kelola, Risiko, dan Kepatuhan dapat bejalan secara efektif dan selaras dengan Strategi, maka disarankan adanya suatu pendekatan sistem atau model kerangka kerja yang terintegrasi, yang disebut: "GRC-Strategy". GRC-Strategy merupakan suatu model kerangka kerja terintegrasi (Integrated Model Framework) yang mengintegrasikan Tata Kelola (Governance), Risiko (Risk), dan Kepatuhan (Compliance) ke dalam Strategi Korporasi (Corporate Stratgey). Secara umum, esensi GRC-Strategy meliputi empat prinsip, sebagai berikut:

a. Prinsip 1: Dalam menjalankan organisasinya-agar berjalan secara efektif dan efisien-, Perusahaan harus menyusun kebijakan, pedoman, prosedur, dan standar operasi. Perusahaan memerlukan Tata Kelola Perusahaan yang Baik (Good Corporate Governance-GCG) - Governance Issues.

b) Prinsip 2: Dimanapun lokasinya berada, dan pada level apa dalam organisasi, Perusahaan harus patuh pada hukum dan peraturan yang berlaku. Kegagalan untuk mematuhinya, akan dikenakan sanksi. Untuk itu Parusahaan dalam menjalankan operasi bisnisnya harus selalu mematuhi berbagai hukum dan peraturan perundang-undangan yang berlaku Compliance Issues.

c) Prinsip 3: Dalam menjalan operasi bisnisnya, Perusahaan akan menghadapi risiko atas pelanggaran terhadap hukum dan peraturan perundang-undangan yang berlaku. Perusahaan juga akan menghadapi risiko atas tidak berjalannya Tata Kelola Perusahaan sesuai yang diharapkan atau peristiwa eksternal diluar kendali Manajemen. Untuk itu Perusahaan harus mengelola risiko pada seluruh level organisasi - Risk Issues.

d) Prinsip 4: Perusahaan harus berusaha keras untuk mencapai dan mempertahankan keunggulan daya saing berkelanjutan (sustainable competitive advantage), melalui: (1) Secara kontinyu menyesuaikan terhadap adanya perubahan lingkungan eksternal dan internal, dan (2) Secara efektif memformulasikan, mengimplementasikan, dan mengevaluasi serta mengendalikan strategi dengan menerapkan Tata Kelola, Risiko, dan Kepatuhan secara terintegrasi - Strategy Issues. 


\section{KESIMPULAN DAN SARAN}

Dari hasil kajian terhadap hasil Hasil Asesmen Penerapan GCG Tahun 2020 pada PT ABC yang telah dibahas, dapat diperoleh kesimpulan bahwa secara keseluruhan penerapan GCG di PT ABC telah berjalan dengan sangat baik. Namun demikian, masih terdapat beberapa area untuk dilakukan perbaikan (area for improvement), yang dikelompokkan dalam empat bidang, yaitu:

1. Tata Kelola (Governance)

2. Manajemen Risiko (Risk Management)

3. Kepatuhan (Compliance)

4. Strategi (Strategy).

\section{REFERENSI}

David, F.R. and David, F.R.(2017). Strategic Management: A Competitive Advantage Approach, Concepts and Cases (16 Th Edition). England, Pearson.

Keputusan Sekretaris Kementerian BUMN Nomor: SK-16/S.MBU/2012. Tanggal 06 Juni 2012, tentang Indikator/Parameter Penilaian dan Evaluasi atas Penerapan Tata Kelola Perusahaan Yang Baik (Good Corporate Governance) pada BUMN

Laporan Hasil Assessment Penerapan Good Corporate Governance (GCG) Tahun 2020 PT Pelita Air Service

Materi Workshop GRC-Strategy: Mengintegrasikan Governance, Risk, \& Compliance dalm Strategy, Bandung, 28-29 Maret 2019- JSM Management Consultant

Moeller, R. Robert. (2011) COSO Enterprise Risk management: Establishing Effective Governance, Risk, and Compliance Processes (2 Th Edition). New Jersey, John Wiley \& Sons, Inc.

Peraturan Menteri Negara BUMN Nomor: PER-01/MBU/2011, tanggal 01 Agustus 2011, tentang Penerapan Tata Kelola Perusahaan Yang Baik (Good Corporate Governance) pada BUMN

Peraturan Menteri Negara BUMN Nomor: PER-09/MBU/2012, tanggal 06 Juli 2012 tentang Perubahan atas Peraturan Menteri Negara BUMN Nomor PER-01/2011 tentang Penerapan Tata Kelola Perusahaan Yang Baik ( Good Corporate Governance) pada BUMN

Peraturan Menteri Negara BUMN Nomor: PER-12/MBU/ 2012, tanggal 24 Agustus 2012, tentang Organ Pendukung Dewan Komisaris/Dewan Pengawas

Sarah, R.M. (2017). The benefits of good corporate governance to Small and Medium Enterprises (SMEs) in South Africa: A view on top 20 and bottom 20 JSE listed companies. Problems and Perspectives in Management, Volume 15, Issue 4, 2017.

Sudharmono, J. (2014). Buku Panduan Implementasi GCG Self Assessment. Jakarta. Penerbit: JSM Consultant

Sudharmono, J. (2016). Manajemen Berbasis Sinergi: Studi Kasus Holding BUMN Pupuk dan Semen di Indonesia. Jurnal Manajemen Kwik Kian Gie School of Business Vol. 5 No. 2.

Thompson, A., Peteraf, M., Gamble, J., and Strickland, A. (2018). Crafting \& Executing Strategy: The Quest for Competitive Advantage-Concepts and Cases (21 Th Edition). New York, Mc Graw Hill Education International Edition.

Wheelen, L.T., Hunger, D.J., Hoffman, N.A., Bamford E.C.. (2018). Strategic Management and Business Policy: Globalization, Innovation and Sustainability. United Kingdom, Pearson. 